\title{
Progress in Clinical Research on Gonadotropin- Releasing Hormone Receptor Antagonists for the Treatment of Prostate Cancer
}

This article was published in the following Dove Press journal:

Drug Design, Development and Therapy

\author{
Yi-Fu Liu \\ Sheng-Qiang Fu \\ Yu-Chang Yan \\ Bin-Bin Gong \\ Wen-Jie Xie \\ Xiao-Rong Yang \\ Ting Sun \\ Ming $\mathrm{Ma}$
}

Department of Urology, The First Affiliated Hospital of Nanchang University, Nanchang, 330000, Jiangxi

Province, People's Republic of China
Correspondence: Ming Ma Department of Urology, The First Affiliated Hospital of Nanchang University, Nanchang, 330000, Jiangxi Province, People's Republic of China Email mmI5070835359@I63.com

\begin{abstract}
Gonadotropin-releasing hormone $(\mathrm{GnRH})$ receptor agonists are still the most commonly used androgen deprivation treatment (ADT) drugs for prostate cancer in clinical practice. Currently, the $\mathrm{GnRH}$ receptor antagonists used for endocrine therapy for prostate cancer primarily include degarelix and relugolix (TAK-385). The former is administered by subcutaneous injection, while the latter is an oral drug. Compared to GnRH agonists, GnRH antagonists reduce serum testosterone levels more rapidly without an initial testosterone surge or subsequent microsurges. This review focuses on the mechanism of action of GnRH antagonists and agonists, the developmental history of GnRH antagonists, and emerging data from clinical studies of the two antagonists used as endocrine therapy for prostate cancer. Keywords: gonadotropin-releasing hormone, prostate cancer, degarelix, relugolix
\end{abstract}

\section{Introduction}

Prostate cancer is one of the most common malignant tumours in men, and its incidence ranks second among all malignant tumours in men worldwide. ${ }^{1}$ The latest research shows that the incidence and mortality of prostate cancer in most countries in the world have reached a relatively stable state after years of growth. ${ }^{2}$ However, due to the insidious onset of prostate cancer, many patients are already in the advanced stage when they are diagnosed. Since Huggins and Hodges discovered that the growth of prostate cancer cells requires testosterone in $1941,{ }^{3}$ by the end of the $1970 \mathrm{~s}$, surgical castration was commonly used as androgen deprivation therapy (ADT) to achieve castration levels of testosterone in the treatment of advanced prostate cancer. ${ }^{4}$ In 1971 , Schally et al completed the isolation and structural identification of luteinizing hormone releasing hormone $(\mathrm{LHRH}),{ }^{5}$ demonstrating for the first time that both natural and synthetic forms of LHRH can successfully stimulate the release of luteinizing hormone $(\mathrm{LH})$ and follicle stimulating hormone (FSH) in mammals, including humans. ${ }^{6}$ This major discovery has opened a new era of endocrine therapy for prostate cancer, and surgical castration has gradually been replaced by medical castration due to the irreversibility and the psychological impact of surgical castration on patients. At present, more than 6000 LHRH agonists and hundreds of LHRH antagonists have been synthesized worldwide, and these drugs have become the basic for advanced prostate cancer treatment. The objective of this study was to review GnRH antagonists' and agonists' mechanisms of action, the developmental history of GnRH antagonists, and emerging data from clinical studies of the two antagonists in endocrine therapy for prostate cancer. 


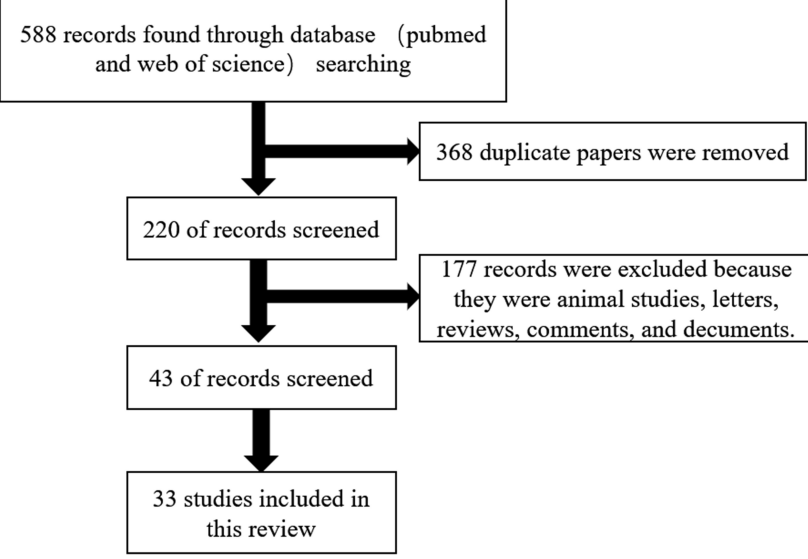

Figure I Flow diagram of evidence collection.

\section{Materials and Methods}

PubMed and Web of Science were used to search for "degarelix" and "relugolix", and keywords included "degarelix", "relugolix", "GnRH antagonist", “degarelix AND prostate cancer", "relugolix AND prostate cancer" and "GnRH antagonists AND prostate cancer". We also reviewed any useful references cited in the retrieved papers, and papers on animal research, letters, comments, reviews, and duplicate papers were excluded. The selection process is described in the flow chart (Figure 1), and a total of 33 clinical studies were included in this review, including 9 Phase III clinical trials.

\section{Mechanism of Action}

Gonadotropin-releasing hormone (GnRH) agonists, which were first applied in the 1980s, are currently the most widely used ADT drugs; they primarily activate GnRH receptors of the hypothalamic-pituitary-gonadal axis and produce excessive and constant stimulation, overcoming pulsatile GnRH control, which leads to downregulation and desensitization of GnRH receptors, and finally, negative feedback that reduces serum testosterone levels. ${ }^{7}$ However, in the first $1-2$ weeks of initial administration, these treatments cause a sharp increase in serum testosterone levels, which can stimulate the rapid growth of tumour cells and cause a series of clinical symptoms, such as bone pain, worsening symptoms of lower urinary tract obstruction, spinal cord compression and even some fatal adverse events. ${ }^{8}$ In the early stage of the maintenance dose injection, there may be fluctuations in serum testosterone levels. Therefore, it is necessary to routinely combine these treatments with non-steroidal anti-androgen drugs, such as bicalutamide and flutamide, in clinical practice; ${ }^{9}$ however, it is impossible to completely avoid the above effects. Unlike GnRH agonists, GnRH antagonists competitively bind to $\mathrm{GnRH}$ receptors in the anterior pituitary and quickly inhibit the excitatory effects of endogenous GnRH on the pituitary, directly blocking the secretion of FSH and LH within a few hours and reducing serum testosterone levels. $^{7}$

\section{The History of GnRH Antagonists}

Since 1972, hundreds of GnRH antagonists have been synthesized, and a series of related animal experiments have been performed. Early GnRH antagonists are hydrophilic and induce the release of histamine, leading to transient oedema and other severe allergic-like reactions. $^{10}$ To eliminate this unfavourable oedemapromoting effect, Schally et al synthesized new analogues using D-ureidoalkyl amino acids. ${ }^{11}$ Among these antagonists without obvious oedema-promoting effects, cetrorelix was found to have the highest overall inhibitory activity and receptor binding affinity. ${ }^{10}$ In 1994, cetrorelix became the first GnRH antagonist to be tested in prostate cancer patients. $^{12,13}$ Although its clinical efficacy has been confirmed, it has associated adverse events, such as oedemapromoting effects and allergic reactions. Furthermore, it is difficult to manufacture long-acting preparations, so it ultimately failed to enter the market. Next, abarelix was approved by the US Food and Drug Administration (FDA) to enter the market in 2003 and was the first GnRH antagonist used to treat advanced prostate cancer; however, due to the same adverse reactions, ${ }^{14}$ it was ultimately not widely used. In 2008, degarelix was approved by the FDA as a next-generation GnRH antagonist; compared to previous generations, histamine release characteristics were greatly reduced, so it is widely used in the US and European markets. In 2019, degarelix was launched in China, becoming China's first first-line GnRH antagonist for endocrine therapy of prostate cancer. In 2020, the new oral GnRH antagonist relugolix (TAK-385) completed a phase III clinical trial for the treatment of advanced prostate cancer, demonstrating good safety and efficacy. ${ }^{15}$ It may be expected to become another option for prostate cancer ADT.

\section{Degarelix \\ Dose Identification Study}

Regarding selection of the optimal dose of degarelix for the one-month depot formulation, three open-label, 
randomised, parallel-group, Phase II clinical trials were conducted. In Europe and South Africa, the initial dose of $240 \mathrm{mg}$ obtained better testosterone suppression than the $200 \mathrm{mg}$ group within one month. During the one-year observation, it was found that in the maintenance dose, the castration rates of the $160 \mathrm{mg}, 120 \mathrm{mg}$, and $80 \mathrm{mg}$ groups were $100 \%, 96 \%$, and $92 \%$, respectively. ${ }^{16}$ In North America, a clinical study involving 128 patients demonstrated that the maintenance dose of the $80 \mathrm{mg}$ group was better than the $60 \mathrm{mg}$ group in terms of testosterone suppression. ${ }^{17}$ In addition, a Japanese study reported that the efficacy of the $240 / 80 \mathrm{mg}$ degarelix dosing regimen for prostate cancer patients was basically the same as the 240 / $160 \mathrm{mg}$ group. ${ }^{18}$ Taking into account the safety, efficacy and economic benefits of the drug, the $240 / 80 \mathrm{mg}$ dosing regimen eventually became the recommended dosage regimen of the one-month depot formulation. For the 3-month depot formulation of degarelix, after initial subcutaneous injection of $240 \mathrm{mg}$, it was found that the maintenance dose of $480 \mathrm{mg}$ every 84 days had a higher cumulative castration rate than the $360 \mathrm{mg}$ group, ${ }^{19}$ and its safety and efficacy have also been confirmed in subsequent phase III clinical trials. ${ }^{20,21}$ Detailed data are presented in Tables 1 and 2.

\section{Oncology Efficacy \\ Pivotal Phase III Trial (CS2I)}

In a 1-year, multicentre, randomised, open-label phase III trial (CS21), 610 histology-confirmed prostate cancer patients were randomly assigned to the following three

Table I Efficacy of GnRH Receptor Antagonists in a Phase III Clinical Study

\begin{tabular}{|c|c|c|c|c|c|c|c|c|c|}
\hline Study & Years & $\begin{array}{l}\text { Follow- } \\
\text { Up } \\
\text { (Month) }\end{array}$ & Arm & $\mathbf{N}$ & $\begin{array}{l}\text { Cumulative } \\
\text { Castration } \\
(\%)\end{array}$ & $\begin{array}{l}\text { PSA } \\
\text { Failure } \\
\text { (\%) }\end{array}$ & $\begin{array}{l}\text { Overall } \\
\text { Mortality } \\
\text { (\%) }\end{array}$ & $\begin{array}{l}\text { Mean } \\
\text { Decreased } \\
\text { IPSS }\end{array}$ & $\begin{array}{l}\text { Prostate } \\
\text { Volume } \\
\text { Reduction (\%) }\end{array}$ \\
\hline \multirow[t]{2}{*}{ CS2I Klotz et al ${ }^{8}$} & \multirow[t]{2}{*}{2008} & \multirow[t]{2}{*}{12} & $\begin{array}{l}\text { Degarelix } \\
80 / 160 \mathrm{mg}\end{array}$ & 409 & $97.2 / 98.3$ & $8.9 / 14.2$ & 2.0 & $N / A$ & $N / A$ \\
\hline & & & Agonist & 201 & 96.4 & 14.1 & 4.0 & $N / A$ & N/A \\
\hline \multirow{2}{*}{$\begin{array}{l}\text { CS28 Anderson } \\
\text { et } \mathrm{al}^{39}\end{array}$} & \multirow[t]{2}{*}{2013} & \multirow[t]{2}{*}{3} & Degarelix & 27 & $N / A$ & $N / A$ & $N / A$ & $N / A$ & 42.0 \\
\hline & & & Agonist & 13 & $N / A$ & N/A & $N / A$ & $N / A$ & 25.0 \\
\hline \multirow[t]{2}{*}{ CS30 Mason et al ${ }^{40}$} & \multirow[t]{2}{*}{2013} & \multirow[t]{2}{*}{3} & Degarelix & 181 & $N / A$ & $N / A$ & $\mathrm{~N} / \mathrm{A}$ & 6.0 & 36.0 \\
\hline & & & Agonist & 64 & $N / A$ & $N / A$ & $N / A$ & 3.4 & 35.3 \\
\hline \multirow[t]{2}{*}{ CS3I Axcrona et al ${ }^{38}$} & \multirow[t]{2}{*}{2012} & \multirow[t]{2}{*}{3} & Degarelix & 81 & $N / A$ & $\mathrm{~N} / \mathrm{A}$ & $N / A$ & 6.7 & 37.2 \\
\hline & & & Agonist & 92 & $\mathrm{~N} / \mathrm{A}$ & $N / A$ & $\mathrm{~N} / \mathrm{A}$ & 4.0 & 39.0 \\
\hline \multirow[t]{2}{*}{ CS35 Tombal et al ${ }^{21}$} & \multirow[t]{2}{*}{2012} & \multirow[t]{2}{*}{12} & Degarelix & 565 & $N / A$ & 13.5 & $\mathrm{~N} / \mathrm{A}$ & $\mathrm{N} / \mathrm{A}$ & $N / A$ \\
\hline & & & Agonist & 283 & $N / A$ & 13.5 & $N / A$ & $N / A$ & $N / A$ \\
\hline \multirow[t]{2}{*}{ CS42 You et al ${ }^{35}$} & \multirow[t]{2}{*}{2015} & \multirow[t]{2}{*}{7} & $\begin{array}{l}\text { CS42 } \\
\text { Degarelix }\end{array}$ & 155 & 96.7 & 2.7 & $N / A$ & $N / A$ & $N / A$ \\
\hline & & & $\begin{array}{l}\text { CS2I } \\
\text { Degarelix }\end{array}$ & 207 & 99.0 & 2.1 & $N / A$ & N/A - & $N / A$ \\
\hline \multirow[t]{2}{*}{ Ozono et $\mathrm{al}^{20}$} & \multirow[t]{2}{*}{2018} & \multirow[t]{2}{*}{12} & Degarelix & 117 & 95.1 & 2.6 & 0 & N/A & $N / A$ \\
\hline & & & Agonist & 117 & 100.0 & 0.9 & 0.9 & $N / A$ & $N / A$ \\
\hline \multirow[t]{2}{*}{ Sun et $\mathrm{al}^{34}$} & \multirow[t]{2}{*}{2019} & \multirow[t]{2}{*}{12} & Degarelix & 143 & 97.0 & 17.2 & $N / A$ & 5.9 & $N / A$ \\
\hline & & & Agonist & 142 & 93.4 & 26.6 & $N / A$ & 5.2 & $N / A$ \\
\hline \multirow[t]{2}{*}{ Shore et $\mathrm{al}^{15}$} & \multirow[t]{2}{*}{2020} & \multirow[t]{2}{*}{12} & Relugolix & 622 & 96.7 & $N / A$ & N/A & $\mathrm{N} / \mathrm{A}$ & $\mathrm{N} / \mathrm{A}$ \\
\hline & & & Agonist & 308 & 98.0 & $N / A$ & $N / A$ & N/A & $N / A$ \\
\hline
\end{tabular}

Abbreviations: PSA, prostate specific antigen; IPSS, International Prostate Symptom Score. 
Table 2 Adverse Effects of GnRH Receptor Antagonist in a Phase III Clinical Study

\begin{tabular}{|c|c|c|c|c|c|c|c|c|c|}
\hline Study & Years & $\begin{array}{l}\text { Follow-Up } \\
\text { (Month) }\end{array}$ & Arm & $\mathbf{N}$ & $\begin{array}{l}\text { AEs } \\
\text { (\%) }\end{array}$ & $\begin{array}{l}\text { Hot } \\
\text { Flash } \\
\text { (\%) }\end{array}$ & $\begin{array}{l}\text { Injection Site } \\
\text { Reaction (\%) }\end{array}$ & $\begin{array}{l}\text { Musculoskeletal } \\
\text { Events (\%) }\end{array}$ & $\begin{array}{l}\text { CV } \\
\text { Events } \\
\text { (\%) }\end{array}$ \\
\hline \multirow[t]{2}{*}{ CS2I Klotz et al ${ }^{8}$} & \multirow[t]{2}{*}{2008} & \multirow[t]{2}{*}{12} & $\begin{array}{l}\text { Degarelix } \\
80 / 160 \mathrm{mg}\end{array}$ & 409 & 81.0 & 26.0 & 40.0 & 11.0 & 9.0 \\
\hline & & & Agonist & 201 & 78.0 & 21.0 & 0.5 & 19.0 & 13.0 \\
\hline \multirow[t]{2}{*}{ CS28 Anderson et al ${ }^{39}$} & \multirow[t]{2}{*}{2013} & \multirow[t]{2}{*}{3} & Degarelix & 27 & 52.0 & 19.0 & 33.0 & 0 & $\mathrm{~N} / \mathrm{A}$ \\
\hline & & & Agonist & 13 & 54.0 & 15.0 & 0 & 15.0 & $\mathrm{~N} / \mathrm{A}$ \\
\hline \multirow[t]{2}{*}{$\operatorname{CS} 30$ Mason et al ${ }^{40}$} & \multirow[t]{2}{*}{2013} & \multirow[t]{2}{*}{3} & Degarelix & 181 & 78.0 & 60.0 & 33.0 & $\mathrm{~N} / \mathrm{A}$ & $\mathrm{N} / \mathrm{A}$ \\
\hline & & & Agonist & 64 & 73.0 & 63.0 & 2.0 & $N / A$ & $N / A$ \\
\hline \multirow[t]{2}{*}{ CS3I Axcrona et al $\left.\right|^{38}$} & \multirow[t]{2}{*}{2012} & \multirow[t]{2}{*}{3} & Degarelix & 81 & 39.0 & 10.0 & 15.0 & 4.6 & 0 \\
\hline & & & Agonist & 92 & 48.0 & 17.0 & 0 & 7.4 & I.I \\
\hline \multirow[t]{2}{*}{ CS35 Tombal et $\mathrm{al}^{21}$} & \multirow[t]{2}{*}{2012} & \multirow[t]{2}{*}{12} & Degarelix & 565 & 75.0 & N/A & 39.0 & 14.0 & $\mathrm{~N} / \mathrm{A}$ \\
\hline & & & Agonist & 283 & 71.0 & $N / A$ & 2.0 & 20.0 & $N / A$ \\
\hline \multirow[t]{2}{*}{ CS42 You et $\mathrm{al}^{35}$} & \multirow[t]{2}{*}{2015} & \multirow[t]{2}{*}{7} & $\begin{array}{l}\text { CS42 } \\
\text { Degarelix }\end{array}$ & 156 & 72.0 & 3.0 & 22.0 & $N / A$ & $N / A$ \\
\hline & & & $\begin{array}{l}\text { CS2I } \\
\text { Degarelix }\end{array}$ & 207 & 70.0 & 22.0 & 27.0 & $N / A$ & $N / A$ \\
\hline \multirow[t]{2}{*}{ Ozono et $\mathrm{al}^{20}$} & \multirow[t]{2}{*}{2018} & \multirow[t]{2}{*}{12} & Degarelix & 117 & 100.0 & 23.1 & 75.0 & 5.1 & $N / A$ \\
\hline & & & Agonist & 117 & 91.0 & 32.5 & 6.0 & 4.3 & N/A \\
\hline \multirow[t]{2}{*}{ Sun et $\mathrm{al}^{34}$} & \multirow[t]{2}{*}{2019} & \multirow[t]{2}{*}{12} & Degarelix & 143 & 76.1 & $N / A$ & 35.0 & 7.7 & 7.7 \\
\hline & & & Agonist & 142 & 58.9 & $N / A$ & 0.7 & 10.6 & 10.6 \\
\hline \multirow[t]{2}{*}{ Shore et al ${ }^{15}$} & \multirow[t]{2}{*}{2020} & \multirow[t]{2}{*}{12} & Relugolix & 622 & 92.9 & 54.3 & $\mathrm{~N} / \mathrm{A}$ & $\mathrm{N} / \mathrm{A}$ & 2.9 \\
\hline & & & Agonist & 308 & 93.5 & 51.6 & N/A & N/A & 6.3 \\
\hline
\end{tabular}

Abbreviations: AEs, adverse events; CV, cardiovascular.

groups: $240 \mathrm{mg}$ subcutaneous degarelix for 1 month with a monthly maintenance dose of $80 \mathrm{mg}$ or $160 \mathrm{mg}$, or $7.5 \mathrm{mg} /$ month leuprolide was injected intramuscularly. Patients receiving leuprolide were given anti-androgen drugs as appropriate to prevent flares. ${ }^{8}$ The performance of the two different degarelix dosing regimens (240/ $80 \mathrm{mg}$ and $240 / 160 \mathrm{mg}$ ) in the primary endpoint (testosterone suppression) was not inferior to the leuprolide group (Table 1). Three days after the initial injection dose, the castration rates of the $240 / 160 \mathrm{mg}$ group and $240 / 80 \mathrm{mg}$ group were $96.1 \%$ and $95.5 \%$, respectively, while that of the leuprolide group was $0 \%$; on the 14 th day, they were $100 \%, 99.5 \%$, and $18.2 \%$. In addition, $80 \%$ of patients in the leuprolide group had a testosterone surge, compared to $0 \%$ in the degarelix group. Consistent with the changes in testosterone, the prostate-specific antigen (PSA) decline in the $240 / 80 \mathrm{mg}$ and 240/160 mg degarelix groups was also significantly faster than in the leuprolide group and was basically the same as the leuprolide + bicalutamide group. This phenomenon may be attributed to degarelix's ability to also reduce serum adrenal androgen levels in patients with prostate cancer. ${ }^{22}$ Furthermore, in the first $1-2$ weeks of treatment, the median LH and FSH levels of patients in the leuprolide group increased due to the mechanism of action; however, median LH and FSH levels in the degarelix group declined more rapidly after the start of the treatment and remained suppressed until the end of the study. ${ }^{8}$ At the end of the 12-month study, median FSH levels in the $240 / 80 \mathrm{mg}$ degarelix, $240 / 160 \mathrm{mg}$ degarelix and leuprolide groups decreased by $88.5 \%, 89.0 \%$ and $54.8 \%$, respectively. ${ }^{8}$ 


\section{Additional Analyses of CS2I}

In the CS21 study, the incidence of PSA failure (defined as a PSA increase of $\geq 50 \%$ from nadir and $\geq 5 \mathrm{ng} / \mathrm{mL}$ on two consecutive occasions at least 2 weeks apart) during the study was $8.9 \%, 14.2 \%$, and $14.1 \%$ in the $240 / 80 \mathrm{mg}$ degarelix, 240/160 mg degarelix and leuprolide groups, respectively. ${ }^{8}$ Because $240 / 80 \mathrm{mg}$ degarelix is the recommended dosing regimen, Tombal et al conducted an additional analysis of the secondary end point of biochemical recurrence rate and found that patients in the CS21 study had a lower PSA failure rate with $240 / 80 \mathrm{mg}$ degarelix compared to $7.5 \mathrm{mg} / \mathrm{month}$ leuprolide; the difference was most marked in those with baseline PSA $>20 \mathrm{ng} / \mathrm{mL}$ or metastatic prostate cancer. ${ }^{23}$ For changes in serum alkaline phosphatase levels, the decrease in serum alkaline phosphatase in the degarelix $240 / 80 \mathrm{mg}$ group was greater than in the leuprolide group, especially in patients with bone metastases or patients with a baseline PSA level $>50 \mathrm{ng} /$ $\mathrm{mL} .{ }^{24}$ Over 1 year, patients using degarelix always maintained an alkaline phosphatase inhibition state, and there was no increase in serum alkaline phosphatase levels of patients in the late stage, unlike the leuprolide group. ${ }^{24}$

\section{Extension Phase of CS2I}

In recent years, a number of studies have suggested that PSA progression may predict overall survival in prostate cancer patients. ${ }^{25,26}$ In the extension phase of the CS21 study, in addition to its good tolerance and stable testosterone suppression within 5 years, ${ }^{27}$ it was also found that the PSA progression-free survival (PSA-PFS) hazard rate of the degarelix group was relatively lower than the leuprolide group, and the PSA-PFS hazard rate was decreased significantly after patients in the leuprolide group were switched to the degarelix group, while the rate was consistent in patients who continued to use degarelix. ${ }^{27,28}$ Furthermore, studies by Iversen et al showed that degarelix monotherapy also produces a superior effect on PSA-PFS outcome than the GnRH agonist + bicalutamide dosing regimen. ${ }^{29}$ The above findings may indicate that degarelix has certain advantages in delaying the progression of PSA compared to GnRH agonists, although its specific mechanism of action is unclear. ${ }^{23,28,29}$ On the other hand, degarelix reduces LH and FSH levels more directly and rapidly, ${ }^{8}$ and it was confirmed that its inhibition of FSH levels was more profound than leuprolide because FSH levels were further suppressed in patients who switched from the leuprolide group to the degarelix group until levels were similar to those observed during continuous degarelix treatment. ${ }^{28}$ An authoritative study found that FSH receptors are selectively expressed on the surface of blood vessels in a variety of organ tumours, including prostate cancer, ${ }^{30}$ and FSH is considered to play an important role in the growth regulation of prostate cancer cells. ${ }^{31,32}$ A single-centre retrospective study found that there was a trend for a negative correlation between FSH values and the time from hormone-sensitive prostate cancer to castration resistance. ${ }^{33}$ However, there is still a lack of data from large-scale clinical studies on whether prostate cancer patients who use degarelix have better long-term benefits.

\section{Asian Clinical Study}

Recently, major studies of degarelix in Asian populations have also proven its short-term efficacy and safety (shown in Table 1). In a one-year phase III clinical study in China, 273 prostate cancer patients were randomised in a 1:1 ratio to once-a-month subcutaneous injection of either degarelix $(240 / 80 \mathrm{mg})$ or goserelin $(3.6 \mathrm{mg}) .{ }^{34}$ During the study, treatment with degarelix resulted in more rapid testosterone suppression and PSA reduction versus the goserelin group, and the cumulative castration rate of the degarelix group was 3.6\% higher than the goserelin group, indicating that the primary efficacy of degarelix is at least not inferior to GnRH agonists. Moreover, on day 364, the cumulative probability of PSA-PFS in the degarelix group was higher than in the goserelin group, and the cumulative probability of PFS in the degarelix and goserelin groups was $81.5 \%$ and $71.7 \%$, respectively. ${ }^{34}$ Therefore, degarelix showed a more favourable trend in this study with respect to short-term disease control.

In Japan, a phase III clinical study was performed to evaluate the efficacy and safety of a 3-month dosing regimen of degarelix in prostate cancer patients, and 234 subjects with prostate cancer were randomised to the degarelix and goserelin groups. ${ }^{20}$ The initial dose of $240 \mathrm{mg}$ degarelix or $3.6 \mathrm{mg}$ goserelin was subcutaneously injected; after the 28th day, a maintenance dose of $480 \mathrm{mg}$ degarelix or $10.8 \mathrm{mg}$ goserelin was given every 84 days. In general, compared to goserelin, the degarelix group showed a more rapid decline in serum testosterone, FSH, LH and PSA levels in the early stages of the study, and the primary endpoint (cumulative castration rate from day 28 to day 364) was not significantly different between the two groups. ${ }^{20}$ Since the cumulative castration rate of the goserelin group was $100 \%$, an additional analysis was performed on the $95 \%$ confidence interval to determine the difference in the proportion of castrated subjects, revealing 
that the 3-month formulation of degarelix was not inferior to that of goserelin in 1-year testosterone suppression. ${ }^{20}$ Furthermore, the proportion of subjects with PSA failure within 364 days was also not significantly different between the two groups. ${ }^{20}$ Similarly, in a 7 -month clinical study conducted in South Korea, degarelix's performance in inhibiting serum testosterone levels and reducing PSA was similar to that of $\mathrm{CS} 21 .{ }^{35}$

\section{Pooled Analysis}

Klotz et al conducted a pooled analysis of 5 randomised phase III/IIIb clinical trials comparing degarelix to GnRH agonists in which a total of 1458 patients received either 3 months $(n=467)$ or 12 months $(n=1458)$ of treatment. ${ }^{36}$ Results showed that PSA-PFS was improved in the degarelix group (HR: $0.71 \mathrm{p}=0.017$ ). For patients with a baseline PSA value $>20 \mathrm{ng} / \mathrm{mL}$, the hazard rate of PSAPFS was $0.74(\mathrm{p}=0.052)$. Overall survival (OS) was also higher in the degarelix group (HR: $0.47 ; \mathrm{p}=0.023$ ). In patients with baseline testosterone levels $>2 \mathrm{ng} / \mathrm{mL}$, OS was particularly improved after degarelix treatment (HR: $0.36 \mathrm{p}=0.006) .{ }^{36}$ Recently, Abufaraj et al performed a meta-analysis of the differential impact of GnRH antagonists and agonists on the clinical safety and oncologic outcomes of patients with metastatic prostate cancer. ${ }^{37}$ Results suggested that there was no significant difference in PSA progression between the two groups, but the overall mortality of $\mathrm{GnRH}$ antagonists was lower than that of GnRH agonists (RR: 0.48, 95\% CI: $0.26-0.90, \mathrm{p}=0.02$ ). ${ }^{37}$ Of note, the study of Abufaraj et al included more clinical trials based on Klotz et al Both studies supported the shortterm overall survival benefit of degarelix, but there are different opinions on its control of PSA.

\section{Relief of Lower Urinary Tract Symptoms and Prostate Volume Reduction}

Research on the effects of degarelix on the relief of lower urinary tract symptoms (LUTS) has primarily included three 12-week clinical trials (CS28, CS30, CS31) in nonAsian populations. ${ }^{38-40}$ Regarding the reduction in the International Prostate Symptom Score (IPSS), degarelix was superior to goserelin plus bicalutamide in all three studies (Table 1). In the CS28 study, the reduction in IPSS in the full analysis set and per protocol analysis set of the degarelix group was greater than the goserelin group; ${ }^{39}$ in the CS30 and CS31 studies, compared to the goserelin group, except for the higher mean IPSS decline in the degarelix group, more patients were reported to have an
IPSS decrease $>3$ points. ${ }^{38,40}$ In terms of reducing prostate volume, degarelix also performed better in CS28, but there was no significant difference in CS30 and CS31 compared to goserelin plus bicalutamide. ${ }^{38-40}$ Mason et al conducted a pooled analysis of data from the above three clinical trials and concluded that degarelix did show better efficacy in relieving lower urinary tract symptoms in patients with prostate cancer, ${ }^{41}$ and this advantage may be because degarelix directly inhibits the growth of benign prostatic hyperplasia cells by reducing cell proliferation and increasing apoptosis. ${ }^{42}$ At the same time, the short observation time of the experiment is considered to be the primary shortcoming of the above research, and inconsistency between the relief of LUTS symptoms and changes in prostate volume in the results is considered primarily due to differences in the mechanism of action between the two drugs. ${ }^{41}$ However, in a phase III clinical study in China, the improvement in IPSS was comparable between the two treatment groups over one year. ${ }^{34}$ The difference in the results of the studies in the two regions is due to differences in race or study lengths or selection bias of included patients. Further analysis or more clinical studies are needed to confirm this. However, what we can understand is that the absolute advantage of degarelix in reducing IPSS is still unknown.

\section{Intermittent ADT, Neoadjuvant ADT and Second-Line Hormone Therapy}

Related research on degarelix as an intermittent androgen deprivation therapy for prostate cancer patients has reported good tolerability and efficacy. ${ }^{43}$ During the withdrawal period, the serum PSA levels are suppressed for a longer period of time, while testosterone levels return to normal, allowing improved sexual function. In a phase II randomised multicentre study of patients with biochemical recurrence after radical treatment of prostate cancer, two groups of patients received intermittent androgen deprivation therapy with degarelix induction therapy for 4 months and 10 months, and no difference was observed in the duration of the off-treatment interval or the rate of testosterone recovery. ${ }^{44}$ The above studies indicate that degarelix can be used as a drug for intermittent androgen deprivation therapy, but the optimal induction time needs to be further studied.

Furthermore, a preliminary prospective study evaluated recovery of serum testosterone levels and sexual function in patients with moderate prostate cancer using $\mathrm{GnRH}$ 
antagonists as neoadjuvant therapy before external radiotherapy and found that in most patients, testosterone levels and sexual function returned to normal within 9 months after the last administration. ${ }^{45}$ A retrospective study involving 406 patients suggested that neoadjuvant $\mathrm{GnRH}$ antagonists plus low-dose estramustine phosphate improve the pathological results of high-risk prostate cancer patients and reduce the risk of biochemical recurrence, similar to the effect of GnRH agonists. ${ }^{46}$ Interestingly, a Phase II, randomised, open-label study found that neoadjuvant degarelix alone, compared to the use of an LHRH agonist and bicalutamide, is associated with higher levels of intratumoural dihydrotestosterone (DHT), despite similar testosterone levels. ${ }^{47}$ These unexpected results might suggest that degarelix activates an alternate pathway for de novo androgen synthesis or that bicalutamide has theoretical off-target properties, such as DHT synthesis inhibition or influences DHT glucuronidation. ${ }^{47}$

In addition, a multicentre randomised phase II clinical trial evaluated the efficacy of degarelix as a second-line hormone treatment for prostate cancer. When patients who failed GnRH agonist treatment were switched to degarelix, the 3-month and 12-month effective rates were only $16.7 \%$ $\sim 33.3 \%$ and $8.8 \%$, respectively. ${ }^{48}$ Moreover, the same low response rate to PSA appeared in other studies of the same type, ${ }^{49,50}$ indicating that degarelix has limited effect as a second-line hormone therapy option.

\section{Safety and Tolerability}

In the above series of studies, the overall incidence of adverse events (AEs) in the degarelix group was similar to that in the GnRH agonist group (shown in Table 2). Most reported AEs were of mild to moderate intensity, and hot flashes were the most common AE. 8,27,34 Apart from the onset of hot flashes being faster on degarelix versus leuprolide, no major differences were observed in the overall pattern of hot flashes between the two groups. ${ }^{51}$ In all studies, local injection site allergic reaction (such as pain, erythema, swelling, nodules, etc.) in the degarelix group was significantly higher than in the GnRH agonist group; ${ }^{8,20,27,34,35}$ fortunately, most adverse reactions occurred after the first injection, and the incidence decreased for subsequent maintenance doses. ${ }^{27}$ However, results of the two pooled analyses suggested that the incidence of musculoskeletal AEs, including back pain, myalgia, arthralgia, spinal column stenosis, and fracture, in the degarelix group was lower than in the GnRH agonist group. $^{36,37}$ Furthermore, there were no significant differences in the overall risk of AEs, such as liver enzyme elevation, liver failure, urinary retention, and fatigue, ${ }^{37}$ and recipients of $\mathrm{GnRH}$ agonists had relatively fewer AEs, such as joint pain, fatigue, decreased libido, hot flashes, chills, hyperhidrosis, erectile dysfunction, back pain, weight gain, malaise, fever, anaemia, constipation, nasopharyngitis, and hypertension. ${ }^{37}$

In a study combining data from six clinical trials, compared to GnRH agonists, patients treated with degarelix had a reduced risk of cardiovascular AEs within 1 year after treatment, while those with a history of cardiovascular disease exhibited more significant benefits, ${ }^{52}$ and this advantage was confirmed in a follow-up study in the UK. ${ }^{53}$ Margel et al conducted a phase II clinical study in men with prostate cancer and existing cardiovascular disease, and these men were randomised to receive GnRH agonist or antagonist treatment for 1 year to compare the incidence of cardiovascular events. ${ }^{54}$ The degarelix group and GnRH agonist group consisted of 41 and 39 participants, respectively; $20 \%$ of patients in the GnRH agonist group experienced major cardiovascular and cerebrovascular events, compared to only $3 \%$ in the degarelix group $(p=0.013) .{ }^{54}$ These results seem to be more robust in confirming that degarelix has greater benefits in cardiovascular events for prostate cancer patients who have preexisting cardiovascular disease. However, a recent epidemiological study involving 120,216 prostate cancer patients showed that the use of GnRH agonists and degarelix both increased the risk of cardiovascular disease, while bicalutamide monotherapy did not occur. ${ }^{55}$ Therefore, we think that the cardiovascular risk reduction in patients using degarelix is only relative to that of $\mathrm{GnRH}$ agonists, while the exact effect of degarelix on cardiovascular disease and its mechanism needs to be further studied.

\section{Quality of Life Benefits}

Lee et al measured health-related quality of life in 610 patients enrolled in the CS21 trial using SF-12 and the European Organisation for Research and Treatment of Cancer quality of life questionnaire-C30. They found that the progression of PSA and musculoskeletal adverse events had the most significant impact on average utility. ${ }^{56}$ However, the results in the above studies suggested that degarelix slows the progress of PSA $^{27,36}$ and reduces the incidence of musculoskeletal events, ${ }^{36,37}$ so it is believed to improve the quality of life of prostate cancer patients. $^{56}$ 


\section{Relugolix}

\section{Phase I and Phase II Clinical Trials}

Relugolix is an oral, highly selective GnRH antagonist that needs to be administered once a day, and its effective half-life is approximately 25 hours. In two phase I clinical studies of relugolix, its efficacy, tolerability, and safety were initially verified, and the minimum initial/maintenance dose required to achieve the expected clinical effect was shown to be 320/ $80 \mathrm{mg} .{ }^{57,58}$ In the subsequent phase II clinical trial, the relugolix group was found to be slightly better than the leuprolide group in terms of inhibiting serum testosterone, lowering PSA levels, and reducing the incidence of AEs. ${ }^{59} \mathrm{In}$ addition, a randomised, open-label, parallel-group phase II trial evaluated the efficacy and safety of relugolix as a neoadjuvant/adjuvant ADT to external beam radiotherapy in patients with localised intermediate-risk prostate cancer. ${ }^{60}$ Both relugolix and degarelix yielded rapid reductions in testosterone not seen with $\mathrm{GnRH}$ agonists. When serum testosterone was $1.73 \mathrm{nmol} / 1$ and $0.7 \mathrm{nmol} / 1$ as the castration threshold, the castration rates of the relugolix group at 24 weeks were $95 \%$ and $82 \%$, respectively and were $89 \%$ and $68 \%$ in the degarelix group. In terms of inhibiting PSA and reducing prostate volume, there was no significant difference between the two groups. For the incidence of AEs, the main disadvantage of the degarelix group was the higher incidence of local injection adverse reactions. There were no obvious differences in other adverse reactions, such as hot flashes, cardiovascular events, or musculoskeletal AEs. Moreover, after stopping drug treatment, the relugolix group returned to normal testosterone levels more quickly than the degarelix group. This advantage is related to its pharmacokinetic characteristics as a daily oral therapy.

\section{Phase III Clinical Trial (HERO)}

Based on the relugolix phase II clinical trial, multiple countries jointly launched a 48-week multicentre, randomised, open-label, phase III trial; the study primarily consisted of relugolix (120 mg once daily after a single oral loading dose of $360 \mathrm{mg}$ ) and leuprolide (22.5 mg [or $11.25 \mathrm{mg}$ in Japan and Taiwan] by injection every 3 months) groups. ${ }^{15}$ For the primary endpoint of the trial (cumulative castration rate at 48 weeks), the relugolix group performed slightly better than the leuprolide group (Table 1). On the 4th day, the cumulative castration rate of the relugolix group was $56.0 \%$, and the cumulative castration rate of the relugolix group was 0 ; on the 15th day, the cumulative castration rate of the relugolix group was $98.7 \%$, and the relugolix group was $12.0 \%$. The cumulative probability of profound castration (serum testosterone $<0.7 \mathrm{nmol} / \mathrm{l}$ ) in the two groups on day 15 was $78.4 \%$ and $1.0 \%$, respectively, and the PSA response rates were $79.4 \%$ and $19.8 \%$, respectively. At all available time points, inhibition of FSH levels in the relugolix group was better than the leuprolide group. In the subgroup that was followed up for testosterone recovery, 90 days after drug withdrawal, mean testosterone levels in the relugolix and leuprolide groups were $288.4 \mathrm{ng} / \mathrm{dl}$ and $58.6 \mathrm{ng} / \mathrm{dl}$, respectively, indicating that patients in the relugolix group returned to normal testosterone levels faster. This advantage suggests that relugolix is more suitable for prostate cancer patients receiving intermittent hormone therapy.

Among all patients, there was no significant difference in the overall incidence of AEs between the two groups (Table 2). The incidence of grade 1 or 2 diarrhoea in the relugolix group was slightly higher than in the leuprolide group; however, the incidence of major cardiovascular AEs in the relugolix group was significantly lower than in the leuprolide group. ${ }^{15}$ In patients with a history of cardiovascular disease, the incidence of cardiovascular AEs in the relugolix group was $3.6 \%(3 / 84)$, while that in the leuprolide group was $17.8 \%(8 / 45) .{ }^{15}$ In conclusion, the above results suggest that relugolix is superior to leuprolide in short-term oncology efficacy and cardiovascular safety.

\section{Conclusions}

In the abovementioned clinical studies, compared to GnRH agonists, degarelix has potential advantages in short-term oncology efficacy, cardiovascular AEs, and musculoskeletal AEs; the main disadvantage of degarelix is the high incidence of AEs at the local injection point. The efficacy and safety of relugolix were initially confirmed in phase III clinical studies, and it is expected to become one of the new options for ADT in prostate cancer. However, many of the above conclusions are based on studies with relatively short follow-up times; additional clinical trials with large sample sizes and longer followup times are needed to further confirm or refute these views.

\section{Data Sharing Statement}

All data are provided in the manuscript from published papers as cited.

\section{Funding}

There is no funding to report. 


\section{Disclosure}

All authors declare that they have no conflicts of interest related to this manuscript.

\section{References}

1. Center MM, Jemal A, Lortet-Tieulent J, et al. International variation in prostate cancer incidence and mortality rates. Eur Urol. 2012;61 (6):1079-1092. doi:10.1016/j.eururo.2012.02.054

2. Culp MB, Soerjomataram I, Efstathiou JA, Bray F, Jemal A. Recent global patterns in prostate cancer incidence and mortality rates. Eur Urol. 2020;77(1):38-52. doi:10.1016/j.eururo.2019.08.005

3. Huggins C, Hodges CV. Studies on prostatic cancer. I. The effect of castration, of estrogen and of androgen injection on serum phosphatases in metastatic carcinoma of the prostate. 1941. J Urol. 2002;167 (2 Pt 2):948-951. doi:10.1016/S0022-5347(02)80307-X

4. Rick FG, Block NL, Schally AV. Agonists of luteinizing hormone-releasing hormone in prostate cancer. Expert Opin Pharmacother. 2013;14(16):2237-2247. doi:10.1517/14656566.201 3.834328

5. Schally AV, Arimura A, Baba Y, et al. Isolation and properties of the FSH and LH-releasing hormone. Biochem Biophys Res Commun. 1971;43(2):393-399. doi:10.1016/0006-291X(71)90766-2

6. Schally AV, Arimura A, Kastin AJ, et al. Gonadotropin-releasing hormone: one polypeptide regulates secretion of luteinizing and follicle-stimulating hormones. Science. 1971;173(4001):1036-1038. doi:10.1126/science.173.4001.1036

7. Rick FG, Schally AV. Bench-to-bedside development of agonists and antagonists of luteinizing hormone-releasing hormone for treatment of advanced prostate cancer. Urol Oncol. 2015;33(6):270-274. doi:10.1016/j.urolonc.2014.11.006

8. Klotz L, Boccon-Gibod L, Shore ND, et al. The efficacy and safety of degarelix: a 12-month, comparative, randomized, open-label, parallel-group phase III study in patients with prostate cancer. BJU Int. 2008;102(11):1531-1538. doi:10.1111/j.1464-410X.2008.08183.x

9. Tsushima T, Nasu Y, Saika T, et al. Optimal starting time for flutamide to prevent disease flare in prostate cancer patients treated with a gonadotropin-releasing hormone agonist. Urol Int. 2001;66 (3):135-139. doi:10.1159/000056592

10. Schally AV. Luteinizing hormone-releasing hormone analogs: their impact on the control of tumorigenesis. Peptides. 1999;20 (10):1247-1262. doi:10.1016/S0196-9781(99)00130-8

11. Bajusz S, Kovacs M, Gazdag M, et al. Highly potent antagonists of luteinizing hormone-releasing hormone free of edematogenic effects. Proc Natl Acad Sci U S A. 1988;85(5):1637-1641. doi:10.1073/ pnas.85.5.1637

12. Gonzalez-Barcena D, Vadillo-Buenfil M, Cortez-Morales A, et al. Luteinizing hormone-releasing hormone antagonist cetrorelix as primary single therapy in patients with advanced prostatic cancer and paraplegia due to metastatic invasion of spinal cord. Urology. 1995;45(2):275-281. doi:10.1016/0090-4295(95) 80018-2

13. Gonzalez-Barcena D, Vadillo-Buenfil M, Gomez-Orta F, et al. Responses to the antagonistic analog of LH-RH (SB-75, Cetrorelix) in patients with benign prostatic hyperplasia and prostatic cancer. Prostate. 1994;24(2):84-92. doi:10.1002/pros.2990240206

14. Shore ND, Abrahamsson PA, Anderson J, Crawford ED, Lange P. New considerations for ADT in advanced prostate cancer and the emerging role of GnRH antagonists. Prostate Cancer Prostatic Dis. 2013;16(1):7-15. doi:10.1038/pcan.2012.25

15. Shore ND, Saad F, Cookson MS, et al. Oral relugolix for androgen-deprivation therapy in advanced prostate cancer. $N$ Engl J Med. 2020;382(23):2187-2196. doi:10.1056/NEJMoa20 04325
16. Van Poppel H, Tombal B, de la Rosette JJ, Persson BE, Jensen JK, Kold Olesen T. Degarelix: a novel gonadotropin-releasing hormone $(\mathrm{GnRH})$ receptor blocker-results from a 1-yr, multicentre, randomised, Phase 2 dosage-finding study in the treatment of prostate cancer. Eur Urol. 2008;54(4):805-813. doi:10.1016/j.eururo.2008. 04.065

17. Gittelman M, Pommerville PJ, Persson BE, Jensen JK, Olesen TK. A 1-year, open label, randomized phase II dose finding study of degarelix for the treatment of prostate cancer in North America. $J$ Urol. 2008;180(5):1986-1992. doi:10.1016/j.juro.2008.07.033

18. Ozono S, Ueda T, Hoshi S, et al. The efficacy and safety of degarelix, a GnRH antagonist: a 12-month, multicentre, randomized, maintenance dose-finding phase II study in Japanese patients with prostate cancer. Jpn J Clin Oncol. 2012;42(6):477-484. doi:10.1093/jjco/hys035

19. Ozono S, Tsukamoto T, Naito S, et al. Efficacy and safety of a 3 -month dosing regimen of degarelix in Japanese patients with prostate cancer: a phase II maintenance-dose-finding study. Jpn J Clin Oncol. 2017;47(5):438-446. doi:10.1093/jjco/hyx011

20. Ozono S, Tsukamoto T, Naito S, et al. Efficacy and safety of 3-month dosing regimen of degarelix in Japanese subjects with prostate cancer: a phase III study. Cancer Sci. 2018;109(6):1920-1929. doi:10.1111/ cas. 13600

21. Tombal B, Tammela TLJ, Wolff JM, et al. P109 Efficacy and safety of a 3-monthly depot of degarelix compared with goserelin in prostate cancer. Eur Urol Suppl. 2012;11(5):228-229. doi:10.1016/S1569-9056(13) 60476-5

22. Miyazawa Y, Sekine Y, Syuto T, et al. A gonadotropin-releasing hormone antagonist reduces serum adrenal androgen levels in prostate cancer patients. BMC Urol. 2017;17(1):70. doi:10.1186/s12894-017-0261-z

23. Tombal B, Miller K, Boccon-Gibod L, et al. Additional analysis of the secondary end point of biochemical recurrence rate in a Phase 3 trial (CS21) comparing degarelix $80 \mathrm{mg}$ versus leuprolide in prostate cancer patients segmented by baseline characteristics. Eur Urol. 2010;57(5):836-842. doi:10.1016/j.eururo.2009.11.029

24. Schroder FH, Tombal B, Miller K, et al. Changes in alkaline phosphatase levels in patients with prostate cancer receiving degarelix or leuprolide: results from a 12-month, comparative, phase III study. BJU Int. 2010;106(2):182-187. doi:10.1111/j.1464-410X.2009.08981.x

25. Hussain M, Goldman B, Tangen C, et al. Prostate-specific antigen progression predicts overall survival in patients with metastatic prostate cancer: data from southwest oncology group trials 9346 (intergroup study 0162) and 9916. J Clin Oncol. 2009;27(15):2450-2456. doi:10.1200/JCO.2008.19.9810

26. Hussain M, Tangen CM, Higano C, et al. Absolute prostate-specific antigen value after androgen deprivation is a strong independent predictor of survival in new metastatic prostate cancer: data from southwest oncology group trial 9346 (INT-0162). J Clin Oncol. 2006;24(24):3984-3990. doi:10.1200/JCO.2006.06.4246

27. Crawford ED, Shore ND, Moul JW, et al. Long-term tolerability and efficacy of degarelix: 5-year results from a phase III extension trial with a 1-arm crossover from leuprolide to degarelix. Urology. 2014;83(5):1122-1128. doi:10.1016/j.urology.2014.01.013

28. Crawford ED, Tombal B, Miller K, et al. A phase III extension trial with a 1-arm crossover from leuprolide to degarelix: comparison of gonadotropin-releasing hormone agonist and antagonist effect on prostate cancer. J Urol. 2011;186(3):889-897. doi:10.1016/j.juro.2011.04.083

29. Iversen P, Damber JE, Malmberg A, Persson BE, Klotz L. Degarelix monotherapy compared with luteinizing hormone-releasing hormone (LHRH) agonists plus anti-androgen flare protection in advanced prostate cancer: an analysis of two randomized controlled trials. Ther Adv Urol. 2016;8(2):75-82. doi:10.1177/ 1756287215621471

30. Radu PDA, Pichon PDC, Camparo MDP, Antoine MDM. Expression of follicle-stimulating hormone receptor in tumor blood vessels. N Engl J Med. 2010;363:1621-1630. doi:10.1056/NEJMoa1001283 
31. Ben-Josef E, Yang SY, Ji TH, et al. Hormone-refractory prostate cancer cells express functional follicle-stimulating hormone receptor (FSHR). J Urol. 1999;161(3):970-976. doi:10.1016/S0022-5347(01)61831-7

32. Crawford ED, Tombal B, Keane T, et al. FSH suppression and tumour control in patients with prostate cancer during androgen deprivation with a GnRH agonist or antagonist. Scand J Urol. 2018;52(5-6):349-357. doi:10.1080/21681805.2018.1522372

33. Hoare D, Skinner TA, Black A, Robert Siemens D. Serum follicle-stimulating hormone levels predict time to development of castration-resistant prostate cancer. Can Urol Assoc J. 2015;9(34):122-127. doi:10.5489/cuaj.2545

34. Sun Y, Xie L, Xu T, et al. Efficacy and safety of degarelix in patients with prostate cancer: results from a phase III study in China. Asian J Urol. 2019.

35. You D, Chung BH, Lee SE, Kim CS. Efficacy and safety of degarelix in Korean patients with prostate cancer requiring androgen deprivation therapy: open-label multicenter phase III study. Prostate Int. 2015;3(1):22-26. doi:10.1016/j.prnil.2015.02.005

36. Klotz L, Miller K, Crawford ED, et al. Disease control outcomes from analysis of pooled individual patient data from five comparative randomised clinical trials of degarelix versus luteinising hormone-releasing hormone agonists. Eur Urol. 2014;66 (6):1101-1108. doi:10.1016/j.eururo.2013.12.063

37. Abufaraj $\mathrm{M}$, Iwata $\mathrm{T}$, Kimura $\mathrm{S}$, et al. Differential impact of gonadotropin-releasing hormone antagonist versus agonist on clinical safety and oncologic outcomes on patients with metastatic prostate cancer: a meta-analysis of randomized controlled trials. Eur Urol. 2020.

38. Axcrona K, Aaltomaa S, da Silva CM, et al. Androgen deprivation therapy for volume reduction, lower urinary tract symptom relief and quality of life improvement in patients with prostate cancer: degarelix vs goserelin plus bicalutamide. BJU Int. 2012;110(11):1721-1728. doi:10.1111/j.1464-410X.2012.11107.x

39. Anderson J, Al-Ali G, Wirth M, et al. Degarelix versus goserelin (+ antiandrogen flare protection) in the relief of lower urinary tract symptoms secondary to prostate cancer: results from a phase IIIb study (NCT00831233). Urol Int. 2013;90(3):321-328. doi:10.1159/000345423

40. Mason M, Maldonado Pijoan X, Steidle C, et al. Neoadjuvant androgen deprivation therapy for prostate volume reduction, lower urinary tract symptom relief and quality of life improvement in men with intermediate- to high-risk prostate cancer: a randomised non-inferiority trial of degarelix versus goserelin plus bicalutamide. Clin Oncol (R Coll Radiol). 2013;25(3):190-196. doi:10.1016/j. clon.2012.09.010

41. Mason M, Richaud P, Bosnyak Z, Malmberg A, Neijber A. Degarelix versus goserelin plus bicalutamide in the short-term relief of lower urinary tract symptoms in prostate cancer patients: results of a pooled analysis. Low Urin Tract Symptoms. 2017;9(2):82-88. doi:10.1111/luts.12114

42. Sakai M, Elhilali M, Papadopoulos V. The GnRH antagonist degarelix directly inhibits benign prostate hyperplasia cell growth. Horm Metab Res. 2015;47(12):925-931. doi:10.1055/s-0035-1555899

43. Boccon-Gibod L, Albers P, Morote J, et al. Degarelix as an intermittent androgen deprivation therapy for one or more treatment cycles in patients with prostate cancer. Eur Urol. 2014;66 (4):655-663. doi:10.1016/j.eururo.2014.05.037

44. Klotz L, Loblaw A, Siemens R, et al. A phase II, randomized, multicenter study comparing 10 months versus 4 months of degarelix therapy in prolonging the off treatment interval in men with localized prostate cancer receiving intermittent androgen deprivation therapy for biochemical recurrence following radical local therapy. $J$ Urol. 2018;200(2):335-343. doi:10.1016/j.juro.2018.03.010

45. Inoue T, Mizowaki T, Kabata D, et al. Recovery of serum testosterone levels and sexual function in patients treated with short-term luteinizing hormone-releasing hormone antagonist as a neoadjuvant therapy before external radiotherapy for intermediate-risk prostate cancer: preliminary prospective study. Clin Genitourin Cancer. 2018;16(2):135-141.e131. doi:10.1016/j.clgc.2017.09.009
46. Hagiwara K, Koie T, Ohyama C, et al. Efficacy of a neoadjuvant gonadotropin-releasing hormone antagonist plus low-dose estramustine phosphate in high-risk prostate cancer: a single-center study. Int Urol Nephrol. 2017;49(5):811-816. doi:10.1007/s11255-017-1546-6

47. Sayyid RK, Evans A, Hersey K, et al. A phase II, randomized, open-label study of neoadjuvant degarelix versus $1 \mathrm{hrh}$ agonist in prostate cancer patients prior to radical prostatectomy. Clin Cancer Res. 2017;23(8):1974-1980. doi:10.1158/1078-0432. CCR-16-1790

48. Miller K, Simson G, Goble S, Persson BE. Efficacy of degarelix in prostate cancer patients following failure on luteinizing hormone-releasing hormone agonist treatment: results from an open-label, multicentre, uncontrolled, phase II trial (CS27). Ther Adv Urol. 2015;7(3):105-115. doi:10.1177/1756287215574479

49. Ezaki T, Kosaka T, Mizuno R, et al. Efficacy of treatment with a GnRH antagonist in prostate cancer patients previously treated with a GnRH agonist. Cancer Chemother Pharmacol. 2015;76 (2):301-306. doi:10.1007/s00280-015-2798-4

50. Masson-Lecomte A, Guy L, Pedron P, et al. A switch from GnRH agonist to GnRH antagonist in castration-resistant prostate cancer patients leads to a low response rate on PSA. World $J$ Urol. 2013;31(2):339-343. doi:10.1007/s00345-012-0841-1

51. Iversen P, Karup C, van der Meulen E, Tanko LB, Huhtaniemi I. Hot flushes in prostatic cancer patients during androgen-deprivation therapy with monthly dose of degarelix or leuprolide. Prostate Cancer Prostatic Dis. 2011;14(2):184-190. doi:10.1038/pcan.2011.11

52. Albertsen PC, Klotz L, Tombal B, Grady J, Olesen TK, Nilsson J. Cardiovascular morbidity associated with gonadotropin releasing hormone agonists and an antagonist. Eur Urol. 2014;65(3):565-573. doi:10.1016/j.eururo.2013.10.032

53. Davey P, Kirby MG. Cardiovascular risk profiles of GnRH agonists and antagonists: real-world analysis from UK general practice. World J Urol. 2020. doi:10.1007/s00345-020-03433-3

54. Margel D, Peer A, Ber Y, et al. Cardiovascular morbidity in a randomized trial comparing Gnrh agonist and gnrh antagonist among patients with advanced prostate cancer and preexisting cardiovascular disease. J Urol. 2019;202(6):1199-1208. doi:10.1097/ JU.0000000000000384

55. Cardwell CR, O'Sullivan JM, Jain S, et al. The risk of cardiovascular disease in prostate cancer patients receiving androgen deprivation therapies. Epidemiology. 2020;31(3):432-440. doi:10.1097/EDE.0000 000000001132

56. Lee D, Nielsen SK, van Keep M, Andersson F, Greene D. Quality of life improvement in patients treated with degarelix versus leuprorelin for advanced prostate cancer. J Urol. 2015;193(3):839-846. doi:10.1016/j.juro.2014.09.098

57. MacLean DB, Shi H, Faessel HM, Saad F. Medical castration using the investigational oral GnRH antagonist TAK-385 (relugolix): phase 1 study in healthy males. J Clin Endocrinol Metab. 2015;100 (12):4579-4587. doi:10.1210/jc.2015-2770

58. Suzuki H, Uemura H, Mizokami A, et al. Phase I trial of TAK-385 in hormone treatment-naive Japanese patients with nonmetastatic prostate cancer. Cancer Med. 2019;8(13):5891-5902. doi:10.1002/cam4. 2442

59. Saad F, Bailen JL, Pieczonka CM, et al. Second interim analysis (IA2) results from a phase II trial of TAK-385, an oral GnRH antagonist, in prostate cancer patients (pts. J Clin Oncol. 2016;34 (2):200. doi:10.1200/jco.2016.34.2_suppl.200

60. Dearnaley DP, Saltzstein DR, Sylvester JE, et al. The oral gonadotropin-releasing hormone receptor antagonist relugolix as neoadjuvant/adjuvant androgen deprivation therapy to external beam radiotherapy in patients with localised intermediate-risk prostate cancer: a randomised, open-label, parallel-group phase 2 trial. Eur Urol. 2020;78(2):184-192. doi:10.1016/j. eururo.2020.03.001 


\section{Publish your work in this journal}

Drug Design, Development and Therapy is an international, peerreviewed open-access journal that spans the spectrum of drug design and development through to clinical applications. Clinical outcomes, patient safety, and programs for the development and effective, safe, and sustained use of medicines are a feature of the journal, which has also been accepted for indexing on PubMed Central. The manuscript management system is completely online and includes a very quick and fair peer-review system, which is all easy to use. Visit http://www. dovepress.com/testimonials.php to read real quotes from published authors.

Submit your manuscript here: https://www.dovepress.com/drug-design-development-and-therapy-journal 